\title{
COMPETÊNCIAS PARA UMA APRENDIZAGEM SIGNIFICATIVA: REFLEXÕES NO CONTEXTO DA EDUCAÇÃO PROFISSIONAL
}

\author{
Nilton Manoel Lacerda Adão ${ }^{1}$ \\ Denise Maria Rengel²
}

\begin{abstract}
RESUMO
Esse estudo caracteriza-se pela reflexão sobre o que significa competência no contexto da Educação Profissional e como pode se constituir uma aprendizagem significativa. Para tanto, realizou-se uma pesquisa bibliográfica que teve como temas principais competência e aprendizagem significativa. O critério de escolha dos temas está associado à necessidade de evidenciar como práticas pedagógicas podem contribuir para uma práxis que considere a objetividade e subjetividade do processo de ensinoaprendizagem. Da reflexão, destacam-se algumas possibilidades de interpretação do que venha ser competência no processo educativo e a caracterização de um processo de ensino-aprendizagem que seja significativo possibilitando a reação e ação em situações reais.
\end{abstract}

Palavras-chave: Educação Profissional. Competência. Aprendizagem significativa.

${ }^{1}$ Mestre, e-mail niltonlacerda@sc.senai.br

²Especialista, e-mail denisemrv@sc.senai.br 


\section{INTRODUÇÃO}

A Educação Profissional (EP), em uma sociedade globalizada e com a economia centrada no conhecimento, constitui um grande valor estratégico para o seu desenvolvimento, assim como condição importante para a qualidade de vida das pessoas. Entretanto, devese estar atento à mudança de paradigma no que se refere à determinação de produtos e serviços, marcada pela adoção de concepções e práticas interativas, participativas do processo produtivo. Esse é um grande desafio, pois exige novas atenções, conhecimentos e habilidades, a fim de garantir formação competente. Para tanto, o processo de ensinoaprendizagem deve oferecer experiências capazes de transformar cidadãos competentes para enfrentar os problemas cada vez mais complexos do mundo do trabalho e da sociedade.

A EP que ao mesmo tempo se caracteriza por preparar para o mercado de trabalho, não pode ser identificada somente por esse pressuposto. Isso porque, como educação antes de tudo, deve garantir ao estudante a capacidade de agir criticamente no seu contexto para ser capaz de transformar a sua realidade. É pertinente e relevante a concepção de Freire (2003) que nas relações do homem na e com a realidade nos atos de criação, recriação e decisão há a dinamização do seu mundo.

Par abarcar questões da competência e da aprendizagem significativa, utilizou-se como método a pesquisa bibliográfica, em que, como observa Severino (2007), consiste em trabalhar com categorias teóricas considerando estudos analíticos. Acredita-se que uma compreensão sobre as formas de aprender pode contribuir para apropriação de conhecimentos. $O$ modelo de educação com base em competência pode se caracterizar pela valorização do indivíduo diante da sua capacidade de agir e interagir com o meio de trabalho. Qual melhor forma de agir e interagir? Qual caminho seguir? A forma como se caracteriza o processo de ensino-aprendizagem é significativo? Como se caracteriza uma educação norteada por competências? As perguntas que orientam esse artigo, não buscam respostas absolutas e sim uma reflexão de como uma educação com base em competências pode servir como uma premissa para a EP na busca da melhor relação humana no e com o trabalho. 


\section{REFLEXÕES TEÓRICAS}

O Governo Federal Brasileiro, no final da década de 1990, propôs um modelo educacional baseado em competências para aprimorar as habilidades necessárias aos processos produtivos (ESLABÃO, 2006). Críticas a este modelo podem ser relacionadas ao período histórico brasileiro que resulta de um processo de reconquista da democracia nas décadas de 1980 e 1990, associado aos problemas econômicos e as necessidade de reestruturação de políticas econômicas alinhadas a casos de incapacidades políticas (Ex. impeachment do Presidente Fernando Collor) e a necessidade de inserção na lógica econômica mundial.

Para Ramos (2001) instaurou-se com a implantação do modelo, uma reforma educativa autoritária alinhada ao modelo neoliberal, do ponto de vista institucional e concepção educativa. A crítica está em eleger uma pedagogia das competências para empregar, considerando um ideário particularista, individualista e imediatista do mercado (RAMOS, 2001). Essa interpretação alinha-se a análise dos processos produtivos do ponto de vista da exploração do capital considerando uma relação entre dominantes e dominados, pertinentes, principalmente aos países de maior desigualdade social. Para Saviani (2003) há contradição quando o saber é um meio de produção que, quando apropriado pelos trabalhadores, contraria a lógica do capital que considera os meios de produção como privativos do empresariado, mas se os trabalhadores não possuem algum tipo de saber não são capazes de produzir.

Para Cêa e Sandri (2008) há um senso comum que associa a ciência e a tecnologia com base na produtividade apresentando para a competência os seguintes pressupostos: a educação é fator determinante para a riqueza dos países e posição sócio-econômica das pessoas; a educação pode harmonizar as relações entre capital e trabalho; o processo educacional é determinado pelas transformações sofridas pela base técnica da produção; o nível de empregabilidade dos trabalhadores pode ser ampliado a partir de habilidades e competências. Para não adentrar nessa discussão, será considerado nesse estudo, primordialmente como se constitui a base teórica para o modelo de educação baseada em competência somente como prática educativa.

Neste sentido, permeiam nas definições de competências aspectos como conceitos, habilidades e atitudes (formação), capacitação, práticas de trabalho, articulação de recursos (mobilização), busca de melhores desempenhos (resultados), questionamento constante, potencial para autodesenvolvimento e interação com outras pessoas (BITENCOURT, 2001).

Zarifian (2001) propõe algumas definições para competência que pode ser destacado no quadro a seguir. 
Quadro 1: Propostas de definição de competência

\begin{tabular}{|c|c|c|}
\hline Proposta & Definição & Detalhamento \\
\hline Competência & $\begin{array}{l}\text { é o "tomar iniciativa" e o } \\
\text { "assumir responsabilidade" } \\
\text { do indivíduo diante de } \\
\text { situações profissionais com } \\
\text { as quais se depara }\end{array}$ & 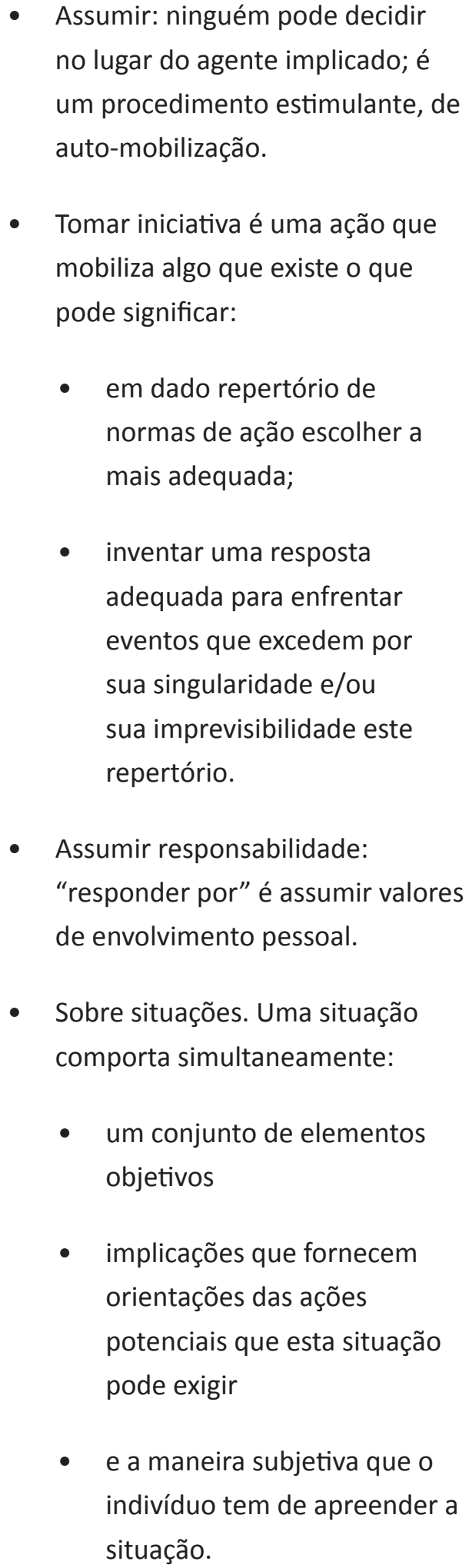 \\
\hline
\end{tabular}




\begin{tabular}{|c|c|c|}
\hline Proposta & Definição & Detalhamento \\
\hline $\begin{array}{l}\text { Competência } \\
\text { (segunda } \\
\text { abordagem) }\end{array}$ & $\begin{array}{l}\text { é um entendimento } \\
\text { prático de situações que se } \\
\text { apóia em conhecimentos } \\
\text { adquiridos e os transforma } \\
\text { na medida em que aumenta } \\
\text { adversidade das situações }\end{array}$ & $\begin{array}{l}\text { Entendimento prático: não } \\
\text { se trata de empregar um } \\
\text { conhecimento prévio, mas de } \\
\text { saber mobilizá-lo judiciosamente } \\
\text { em função da situação. A } \\
\text { dimensão puramente cognitiva } \\
\text { deve ser associada à dimensão } \\
\text { compreensiva. } \\
\text { Que se apóia em conhecimentos } \\
\text { adquiridos: quanto maiores } \\
\text { as dimensões do evento e a } \\
\text { singularidade da situação, mais } \\
\text { os esquemas de conhecimento e } \\
\text { de ação deverão ser mobilizados } \\
\text { de maneira reflexiva. Existe uma } \\
\text { dimensão de incerteza constante } \\
\text { nos conhecimentos possuídos. } \\
\text { E os transforma: a dialética que } \\
\text { se instaura entre competência e } \\
\text { conhecimentos faz precisamente } \\
\text { com que estes últimos se } \\
\text { modifiquem ao contato com } \\
\text { problemas e implicações de uma } \\
\text { situação real de trabalho. } \\
\text { das situações, mais intensamente } \\
\text { serão modificados os } \\
\text { conhecimentos. }\end{array}$ \\
\hline
\end{tabular}




\begin{tabular}{|l|l|}
\hline Proposta & Definição \\
Competência & é a faculdade de mobilizar \\
abordagem) & $\begin{array}{l}\text { redes de atores em torno } \\
\text { das mesmas situações, é a } \\
\text { faculdade de fazer com que } \\
\text { esses atores compartilhem } \\
\text { as implicações de suas } \\
\text { ações, é fazê-los assumir } \\
\text { áreas de co-responsabilidade }\end{array}$
\end{tabular}

\section{Detalhamento}

- Mobilizar redes de atores:

qualquer situação um pouco mais complexa excede as competências de um único indivíduo.

- Compartilhara as implicações de uma situação: de fato os assalariados só se comunicarão entre si e só disponibilizarão suas competências se experimentarem o sentimento de participar das mesmas implicações de uma situação, e se forem avaliados pela chefia à base dessas implicações. Isto não é algo evidente: as segmentações dos campos de responsabilidade e a fixação de objetivos distintos, que marcam as organizações tradicionais tornam difícil esse compartilhar:

- implicações de situações profissionais não serão compartilhadas na medida em que remetem a oposições de interesse;

- implicações que se apóiam na eficiência produtiva da empresa e na relação com categorias específicas da clientela ou dos usuários podem ser compartilhadas. 


\begin{tabular}{|c|c|c|}
\hline Proposta & Definição & Detalhamento \\
\hline & & $\begin{array}{l}\text { É perfeitamente possível } \\
\text { compartilhar as implicações de } \\
\text { atividades sem compartilhar os } \\
\text { mesmos valores. A questão da } \\
\text { comunhão de valores só se coloca } \\
\text { objetivamente para pessoas } \\
\text { envolvidas em relações sólidas de } \\
\text { cooperação, logo, no seio de uma } \\
\text { mesma prática profissional. } \\
\text { Assumir campos de co- } \\
\text { responsabilidade: uma das } \\
\text { características mais inovadoras } \\
\text { da abordagem de competência } \\
\text { reside no fato de ela associar } \\
\text { responsabilidade pessoal e co- } \\
\text { responsabilidade. }\end{array}$ \\
\hline
\end{tabular}

Fonte: Adaptado de Zarifian (2001)

Para o desenvolvimento de competências deve-se se apropriar do conhecimento (saber) em ações do trabalho (saber agir) (BITENCOURT, 2001). No entanto, existem diferentes abordagens educativas com base em competência. Destarte, será apresentada algumas matrizes referenciais pertinentes para essa discussão citadas por Ramos (2001): a condutivista (Estados Unidos da América), a construtivista francesa, a de estrutura comportamentalista ou funcionalista (modelo britânico) e o caso australiano.

Condutivismo: Na concepção condutivista considera-se como elemento central na competência o desempenho efetivo para alcançar resultados e ações específicas de um determinado contexto. Nesse sentido, parte-se da compreensão de como as pessoas podem fazer bem de acordo com os resultados esperados (RAMOS, 2001). No modelo adota-se como exemplo diplomados que obtiveram sucesso (NUNES, 2007).

Construtivismo francês: tem como principal expoente Bertrand Schwartz e apresenta como premissa no desenvolvimento de competências, a reflexão sobre problemas e disfunções encontradas nos processos de trabalho (NUNES, 2007). As competências identificam trabalhadores eficientes ao contexto produtivo e capazes de melhorar situações de trabalho. Para tanto, no processo pedagógico, relaciona-se a formação com o trabalho e o saber com o ser de forma contextualizada com as capacidades de realizar (NUNES, 2007). 
Funcionalismos: No método funcional, os resultados dependem da relação entre problemas, objetivos e a solução. Destarte, com base em competências, analisamse as diferentes relações entre resultados esperados na empresa e habilidades, conhecimentos e atitudes dos trabalhadores (RAMOS, 2001). No método funcional valoriza-se o produto e não o processo sendo considerado mais importante o resultado e não como se chegou a ele. Nunes (2007) observa que nesse caso, competência é o que uma pessoa deve fazer ou que deveria estar em condições de fazer para chegar ao resultado sem se importar como.

Caso australiano: No caso australiano confere-se à competência uma relação de dimensão relacional considerando o contexto e a cultura do local de trabalho incorporando também conhecimentos gerais, profissionais e experiências de trabalho interadas com conhecimentos, habilidades e atitudes individuais. Assim, a competência incorpora conhecimentos, habilidades e atitudes num contexto de tarefas reais que representam níveis de generalidade. Destarte, métodos baseados em problemas são de competências por excelência (RAMOS, 2001)

Do ponto de vista teórico, os franceses abordam o conceito de competência em uma dimensão social e política perpassando pela correlação entre capital e trabalho e considerando a emancipação da formação do trabalhador. A escola americana considera comportamentos observáveis nas atividades do trabalhador (DINATO, 2008). Na escola Britânica considera-se o produto final. No modelo australiano considera-se uma articulação entre processo e resultados para atingir competências. Como uma convergência, está o fato das teorias visarem atender aos interesses industriais. As diferentes abordagens caracterizam-se pelo foco na competitividade e na empregabilidade centrado no indivíduo.

Segundo Saviani (2003) a aprendizagem é influenciada por variáveis individuais e organizacionais em que indivíduos aprendem, se qualificam e tornam as organizações competitivas. Nessa perspectiva, é pertinente levantar algumas críticas referentes às competências gerenciais que podem ser consideradas compatíveis ao modelo de educação. Em seu estudo, Bitencourt (2001), destaca algumas críticas às competências gerenciais que são apresentadas no quadro 2. 
Quadro 2: Críticas às competências gerenciais

\begin{tabular}{|c|c|}
\hline Definição das competências & $\begin{array}{l}\text { O conceito de competência possui diferentes significados e } \\
\text { contradições prevalecendo a construção de atributos (visão } \\
\text { estática) e a falta de visão processual (perspectiva dinâmica) }\end{array}$ \\
\hline Tendência a viver do passado & $\begin{array}{l}\text { As competências são mapeadas considerando a necessidade } \\
\text { do momento sem preocupação com as competências } \\
\text { necessárias para o futuro. }\end{array}$ \\
\hline Qualidade dos atributos & $\begin{array}{l}\text { Consideram-se muitos atributos de competência } \\
\text { (quantidade) com pouco questionamento sobre a qualidade. }\end{array}$ \\
\hline $\begin{array}{l}\text { Falta de atenção para a } \\
\text { qualidade soft }\end{array}$ & $\begin{array}{l}\text { Considera-se atributos efetivos. O que é efetivo? Simplificam- } \\
\text { se questões privilegiando atributos menos significativo, no } \\
\text { entanto, mais fáceis de mensurar. }\end{array}$ \\
\hline $\begin{array}{l}\text { Natureza genérica das } \\
\text { competências }\end{array}$ & Predomina a lista de competências desprovidas de contexto. \\
\hline Burocracia e custo & $\begin{array}{l}\text { Predomina o formalismo voltado à competência e não ao } \\
\text { seu desenvolvimento. }\end{array}$ \\
\hline Falta de orientação futura & Falta de visão integrada considerando novos padrões. \\
\hline Sentir-se competente & $\begin{array}{l}\text { As pessoas precisam sentir-se competentes. Falta espaço a } \\
\text { aprendizagem a partir dos erros ou insucessos. }\end{array}$ \\
\hline Fazer a diferença & $\begin{array}{l}\text { Falta de link entre o significado atribuído e a competência no } \\
\text { ambiente de trabalho. }\end{array}$ \\
\hline “Cenário Skinneriano" & $\begin{array}{l}\text { Estimulo resposta. "Faça isso e tenha aquilo", essa } \\
\text { situação retrata uma visão limitada de competência sendo } \\
\text { manipulativa e pouco construtiva. }\end{array}$ \\
\hline Feedback & Tendência a oferecer elogios e poucas críticas construtivas. \\
\hline
\end{tabular}

Fonte: Adaptado de Bitencourt (2001)

Apesar das críticas das competências estarem alinhadas ao ambiente de trabalho, destacase sua relação intrínseca com a Educação Profissional quando caracterizada pela formação articuladas às características de produção em que o ser humano pode ser produto e produtor da sua realidade. A visão pragmática de "aprender fazendo" com o objetivo de apenas fazer, deve ser substituída pela visão do ser humano como produtor da própria realidade. Para Saviani (2003) conforme o ser-humano modifica o modo de produção, modifica a própria existência humana e muda as formas pelas quais existe. Para tanto, o "currículo escolar, desde a escola elementar, guia-se pelo princípio do trabalho como o processo através do qual o homem transforma a natureza." (SAVIANI, 2003, p. 135). 
No contexto socioeducativo ainda deve-se desconstruir dicotomias como as divergências entre humano x tecnologia e teoria x prática. Para tanto, Saviani (2003) reforça a noção de politecnia para superar as diferenças entre trabalho manual e intelectual e instrução geral e profissional. Um dos pressupostos da educação baseada em competências é que as ações do individuo atendem aos interesses organizacionais do trabalho agregando valor socioeconômico ao processo produtivo como um todo. Dinato (2008), ilustra as competências como fonte de valor para o indivíduo e para a organização.

Figura 1: Competências individuais e organizacionais como fonte de valor

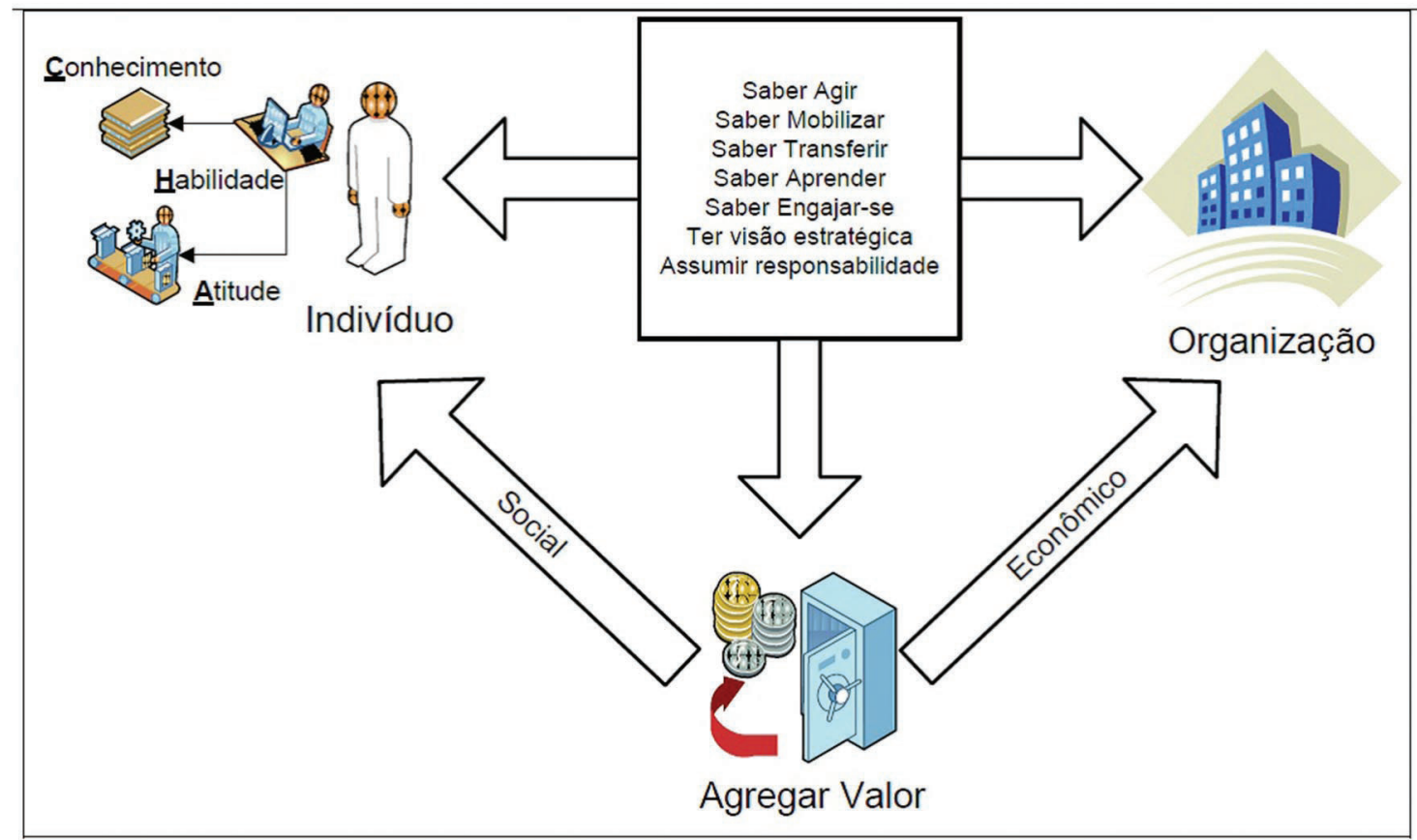

Fonte: Dinato (2008)

Os conhecimentos, habilidades e atitudes são base para o processo de ensino e aprendizagem. Sobre aprendizagem, Seno (2007) fez um estudo considerando as teorias associativistas, em que a aprendizagem consiste em associações entre estímulos e respostas; e as cognitivistas, considerando o indivíduo e sua relação com o meio e como o seu comportamento é influenciado por isso. Constata Seno (2007) que competência difere de qualificação quando diz respeito ao saber fazer e agir no contexto profissional. Para tanto se faz necessário situações profissionais que desenvolvam e consolidem conhecimentos e habilidades. Considerando essa questão no contexto processo ensino e aprendizagem deve-se observar diferentes tipos de aprendizes e diferentes significados à competência. Nesse sentido, o quadro a seguir trata dos significados dados às competências no que se refere ao saber e agir. 
Quadro 3: Saberes que compõem as competências profissionais

\begin{tabular}{|c|c|}
\hline Competência & Significados \\
\hline Saber agir & $\begin{array}{l}\text { - Saber o que fazer } \\
\text { - Saber julgar, escolher, decidir. }\end{array}$ \\
\hline Saber mobilizar & $\begin{array}{l}\text { - Saber mobilizar recursos de pessoas, financeiros, materiais, } \\
\text { criando sinergia entre eles. }\end{array}$ \\
\hline Saber comunicar & $\begin{array}{l}\text { - Compreender, processar, transmitir informações e } \\
\text { conhecimentos, assegurando o entendimento da mensagem } \\
\text { pelos outros. }\end{array}$ \\
\hline Saber aprender & $\begin{array}{l}\text { - Trabalhar o conhecimento e a experiência. } \\
\text { - Rever modelos mentais. } \\
\text { - Saber desenvolver-se e propiciar o desenvolvimento dos } \\
\text { outros. }\end{array}$ \\
\hline Saber comprometer-se & $\begin{array}{l}\text { - Saber engajar-se e comprometer-se com os objetivos da } \\
\text { organização }\end{array}$ \\
\hline $\begin{array}{l}\text { Saber assumir } \\
\text { responsabilidade }\end{array}$ & $\begin{array}{l}\text { - Ser responsável, assumindo os riscos e as consequências de } \\
\text { suas ações, e ser, por isso, reconhecido. }\end{array}$ \\
\hline Ter visão estratégica & $\begin{array}{l}\text { - Conhecer e entender o negócio da organização, seu ambiente, } \\
\text { identificando oportunidades e alternativas. }\end{array}$ \\
\hline
\end{tabular}

Fonte: Fleury e Fleury (2001 apud PAIVA et al. 2011).

Deve-se destacar que não se trata de "adestrar" para o mercado de trabalho, mas de compreender a realidade para poder interagir e modificá-la assim como a própria. Para tanto, é viável a promoção de uma aprendizagem significativa. Para tanto se faz necessário apreender o que é (re)construir o conhecimento, formando conceitos sólidos para agir e reagir diante de situações reais. É por meio da aprendizagem significativa que se concretiza o desenvolvimento das competências. Somente quando o sujeito apreende determinados saberes, consegue mobilizar recursos cognitivos para a resolução de situações problemas ou situações inusitadas. Santos (2010), em seu texto sobre aprendizagem significativa, afirma que a (re)construção do conhecimento se traduz em sete passos: 
O sentir: toda aprendizagem parte de um significado contextual e emocional.

O perceber: após contextualizar, o educando precisa ser levado a perceber as características específicas do que está sendo estudado.

O compreender: é quando se dá a construção do conceito, o que garante a possibilidade de utilização do conhecimento em diversos contextos.

O definir: significa esclarecer um conceito. $O$ aluno deve definir com suas palavras, de forma que o conceito Ihe seja claro.

O argumentar: após definir, o aluno precisa relacionar logicamente vários conceitos e isso ocorre por meio do texto falado, escrito, verbal e não verbal.

O discutir: neste passo, o aluno deve formular uma cadeia de raciocínio por meio da argumentação.

O transformar: o sétimo e último passo da (re)construção do conhecimento é a transformação. A finalidade da aprendizagem significativa é a intervenção na realidade. Sem esse propósito, qualquer aprendizagem é inócua. Neste sentido, é importante levar em conta alguns princípios educativos mais contemporâneos:

a) considerar o estudante como sujeito de sua própria aprendizagem;

b) reconhecer que o conhecimento é construído, progressivamente, por meio da atividade própria de cada sujeito e também pelas interações sociais (entre estudantes, entre professores, entre estudantes e professores);

c) enfatizar a interdisciplinaridade e o desenvolvimento de competências, por meio da construção integrada de saberes e valores que perpassam;

d) respeitar a diversidade dos estudantes, membros de um determinado grupo étnico-cultural e socioeconômico;

e) estimular o desenvolvimento da autonomia do estudante, da sua participação na coletividade, promovendo a criticidade e a cidadania;

f) considerar as experiências e vivências do estudante. Ou seja, os saberes já constituídos, como ponto de partida para as novas aprendizagens.

A partir destas reflexões, em um movimento dialético e democrático, é possível reconstruir, renovar e reeditar uma concepção didático-pedagógica, objetivando o desenvolvimento de novos sujeitos para um novo mundo.

Não se pode desconsiderar que as transformações na sociedade, nas relações sociais e no mundo do trabalho, provocadas pela globalização e inovação tecnológica, têm gerado um impacto no mundo da educação, em especial na educação profissional. Para contextualizar algumas dessas transformações, é pertinente a apresentação do quadro construído por Roglio (1998). 
Quadro 4: Mudança de paradigmas

\begin{tabular}{|l|l|}
\hline \multicolumn{1}{|c|}{ Paradigma atual } \\
Consumo indiscriminado \\
Pessoas que satisfaçam
\end{tabular}

Fonte: Roglio (1998)

Em um contexto de quebra de paradigmas, a atuação do sujeito no trabalho está mudando e, desta forma, desafia a renovação das estruturas e das práticas pedagógicas. Para tanto, as tarefas e atividades devem proporcionar caminhos e desafios apropriados, de tal forma, que criem oportunidades aos estudantes para adquirir confiança em si próprios e na possibilidade de serem bem sucedidos (FERREIRA, 2010). Nesse caso, é relevante uma avaliação clara e realistica, para a aprendizagem do estudante. Para tanto, a forma de avaliar não pode ser limitado em resultados de testes aplicados aos estudantes.

McClelland (1973), em sua crítica aos modelos de testes, relata sua experiência na Etiópia, em 1968, quando no desafio de identificar o quanto os estudantes tinham aprendido de inglês utilizou-se preenchimento de lacunas e questões de múltipla escolha para verificar significado das palavras, formas gramaticais deixando de lado um critério fundamental: a capacidade de usar o inglês para se comunicar. O autor alerta que notas de escola 
não preveem resultados da vida. Uma questão pertinente, na cultura dos testes está na valorização do resultado, muitas vezes sem se saber o porquê, como obrigatoriedade para passar por uma fase da vida escolar. O vestibular é um exemplo. O fato de um indivíduo ser aprovado em primeiro lugar para um curso de medicina não indica que ele será o melhor estudante, muito menos, o melhor profissional.

Para desconstruir a importância dada ao resultado é pertinente a afirmação de Pintrich (2003 apud FERREIRA, 2010) que o desenvolvimento e a aprendizagem não está em perceber-se como o melhor, ou pior, e sim, que se tenha claro o que é capaz ou não de fazer. Nesse sentido, viabiliza-se uma abordagem sistêmica que tem como base a observação considerando que o melhor desempenho de cada parte do sistema (eficiência) não garante o melhor desempenho como um todo (eficácia). Importa como as partes se ajustam e trabalham juntas e o relacionamento com o meio ambiente e outros sistemas (SENO, 2007). Em uma perspectiva sistêmica de aprendizagem, é viável a verificação de Senge (2002) que a capacidade de aprendizagem mistura mudanças comportamentais e técnicas.

É relevante resgatar a afirmação de McKernan (2009) que a educação está no processo. $\mathrm{O}$ quadro 4 mostra a diferença entre o curriculo baseado em resultados e o baseado em processo.

Quadro 5: Caracterísiticas dos modelos

\begin{tabular}{|c|c|}
\hline Modelo baseado em resultados & Modelo baseado no processo \\
\hline Resultado de saída: unidade/lições & $\begin{array}{l}\text { Estabelecimento de metas amplas/ } \\
\text { compreensão }\end{array}$ \\
\hline $\begin{array}{l}\text { Comportamentos dos alunos definidos } \\
\text { como aquilo que eles saberão ou farão }\end{array}$ & $\begin{array}{l}\text { Conteúdo selecionado com base nos } \\
\text { procecimentos e critérios incluídos na disciplina }\end{array}$ \\
\hline $\begin{array}{l}\text { Unidades sequenciadas em modo } \\
\text { lógico }\end{array}$ & Método por unidades não é necessário \\
\hline $\begin{array}{l}\text { Currículo sequenciado em } \\
\text { microunidades }\end{array}$ & Ensino visto como prática reflexiva \\
\hline Ensino direcionado a objetivos & $\begin{array}{l}\text { Estratégia baseada na investigação/descoberta } \\
\text { aberta }\end{array}$ \\
\hline Tempo ajustado para domínio & Compreensão - não-domínio- é a meta \\
\hline A convergência é valorizada & $\begin{array}{l}\text { A divergência/profundidade de pontos de vista } \\
\text { são encorajadas }\end{array}$ \\
\hline Feedback/correções fornecidas & $\begin{array}{l}\text { Resposta criativas/únicas, "não-previstas } \\
\text { respostas" valorizadas }\end{array}$ \\
\hline
\end{tabular}




\begin{tabular}{l|l} 
Modelo baseado em resultados & $\begin{array}{l}\text { Modelo baseado no processo } \\
\text { Avaliação como processo descritivo-qualitativo }\end{array}$ \\
$\begin{array}{l}\text { Avaliação por meio de procedimentos } \\
\text { de medição }\end{array}$ & $\begin{array}{l}\text { e complexo, por exemplo, "se esses rumos } \\
\text { são seguidos com esses materiais, os efeitos } \\
\text { tenderão a ser "X" }\end{array}$ \\
Testes "objetivos" & $\begin{array}{l}\text { Professor como juiz e pesquisador-ação } \\
\text { Indução a formas/campos do conhecimento } \\
\text { Treinamento/instrução }\end{array}$ \\
Uniformidade/comportamentos & $\begin{array}{l}\text { Valoção de diferentes resultados, da } \\
\text { divergência }\end{array}$ \\
terminais previstos & \multicolumn{2}{|l}{}
\end{tabular}

Fonte: Mackernan (2009, p. 105)

Os sujeitos aprendem por múltiplos caminhos e formas de inteligências, utilizandose de diversos meios e modos de expressão. Existe uma expectativa muito grande em relação ao aluno ideal, tanto por parte de instituições de ensino como dos docentes. É importante ressaltar que o fracasso ou insucesso na escola frequentemente leva à evasão escolar. O problema é complexo e está relacionado com alguns fatores, como as formas de avaliação, reprovação escolar, o currículo e as disciplinas escolares. Da mesma forma, como salienta Perrenoud (2001), a coesistência no embiente exige gerenciar além das aprendizagens, o espaço comum, relações, interesses, resistências e a vida cotidiana que não se resume ao ensino e ao trabalho escolar.

A aprendizagem exige a compreensão de significados e sua relação com experiências anteriores e vivências pessoais de cada sujeito, permitindo a formulação de situaçõesproblemas, que incentivem o aprender a aprender, o estabelecimento de diferentes tipos de relações entre fatos, objetos, acontecimentos, noções e conceitos, desencadeando modificações de comportamentos e contribuindo para a utilização do que é aprendido em diferentes situações.

A aprendizagem signitiva pressupõe a valorização de conhecimentos prévios dos sujeitos, para que novas estruturas mentais sejam construídas. Segundo Ausubel; Novak e Hanesian (1980), a aprendizagem significativa ocorre quando uma nova informação relaciona-se de modo não arbitrário com outra informação pré-existente na estrutura cognitiva do aprendiz. Isso implica em dizer que o conhecimento novo e o antigo interagem entre si produzindo um terceiro, modificado. Ou seja, há processo de de construção de novos conhecimentos.

Quando não ocorre a apreensão do conhecimento de maneira significativa, pode-se afirmar que ela foi aprendida de forma mecânica. Diferentemente da aprendizagem significativa, na aprendizagem mecânica as informações não interagem com informações relevantes presentes na estrutura cognitiva, sendo armazenadas de maneira arbitrária e literal. 
Ausubel; Novak e Hanesian (1980) salientam que a aprendizagem significativa apresenta quatro grandes vantagens sobre a aprendizagem por memorização ou mecânica:

a) os conhecimentos adquiridos significativamente ficam retidos por um período maior de tempo;

b) as informações assimiladas resultam num aumento da diferenciação das idéias que serviram de âncoras, aumentando, assim, a capacidade de uma maior facilitação da subseqüente aprendizagem de materiais relacionados;

c) as informações que não são recordadas (são esquecidas), após ter ocorrido a assimilação, ainda deixam um efeito residual no conceito assimilado e, na verdade, em todo o quadro de conceitos relacionados;

d) as informações apreendidas significativamente podem ser aplicadas numa enorme variedade de novos problemas e contextos.

Para tanto, segundo Ausubel; Novak e Hanesian (1980), a teoria da aprendizagem significativa apresenta como princípios norteadores:

a) todo evento educativo envolve aprendiz, professor, conhecimento, contexto e avaliação;

b) os pensamentos, sentimentos e ações estão interligados, positiva ou negativamente; da mesma forma, faz-se necessário disposição para aprender, material potencialmente significativo, algum conhecimento relevante;

c) as atitudes e sentimentos positivos em relação à experiência educativa têm suas raízes na aprendizagem significativa e, por sua vez, facilitam-na;

d) o conhecimento humano é construído, a aprendizagem significativa subjaz a essa construção;

e) o conhecimento prévio do aprendiz tem grande influência sobre a aprendizagem significativa de novos conhecimentos;

f) o ensino deve ser planejado de modo a facilitar a aprendizagem significativa e a ensejar experiências afetivas positivas; e

g) a aprendizagem, assim como o ensino, currículo e contexto devem ser avaliados.

Trabalhar com o conceito de aprendizagem significativa é assumir que o aprender tem um caráter dinâmico que exige ações de ensino direcionadas para que os estudantes internalizem e ampliem os significados elaborados durante as atividades propostas ao longo do processo de ensino-aprendizagem. Portanto, o ensino passa a ser um conjunto de atividades minuciosamente planejadas, em que conteúdo e forma articulam-se de maneira que professor e estudante compartilhem gradativamente de significados relacionados. 


\section{CONSIDERAÇÕES FINAIS}

Visando a reflexão com base nas perguntas apresentadas na introdução, este artigo tratou de uma reflexão teórica, e como tal não apresenta um caráter conclusivo. No entanto, algumas afirmações são pertinentes, como: entender conceitualmente o modelo que orienta a abordagem dada ao processo de ensino e aprendizagem da EP deve ser uma premissa inicial do docente. Isso facilitará a busca da melhor abordagem para construir um processo de ensino-aprendizagem mais adequado ao contexto em que se insere.

As transformações do e no mundo atual são muito dinâmicas, no mundo do trabalho não é diferente. Entender a formação profissional como simples instrumento para atender aos processos produtivos é uma interpretação limitada. Não se pode esquecer que a educação é para sujeitos que ao fazerem parte de um processo de ensino-aprendizagem carregam consigo uma bagagem de informações pré-existentes que associados aos novos conhecimentos assimilados constituem em instrumentos de transformação. Para tanto, a aprendizagem deve ser considerada diante de todas as relações existentes, assim como os diferentes objetivos, e servir como estímulos para uma educação que traga o significado esperado. No entanto, deve-se apresentar aos estudantes situações que sejam potencialmente problemáticas e desequilibradoras, mas que estejam dentro das possibilidades de resolução por parte deles.

Da mesma forma, professores devem estar atentos aos pressupostos que orientam a estrutura curricular proposta e às tendências e transformações sociais do mundo do trabalho sem desconsiderar a história de vida dos envolvidos no processo de ensino e aprendizagem. Nesse caso, deve-se almejar a integração entre sociedade, currículo, processo educativo, relações existentes no processo e formas de avaliação visando ampla compreensão da realidade para valorização de diferentes resultados. Assim, será possível abordar competências que resultem em "melhores práticas" não só no mundo do trabalho, mas também em novas formas de agir e interagir com toda a realidade. 


\title{
LEARNING SKILLS FOR A MEANINGFUL LEARNING: REFLECTIONS IN THE CONTEXT OF PROFESSIONAL EDUCATION
}

\begin{abstract}
This study is characterized by a reflection on what competence means in the context of professional education and how a meaningful learning can be developed. For this reason, we performed a literature research that had, as main themes, competence and meaningful learning. The criterion for the choice of subjects is associated with the need to show how teaching practices can contribute to a practice that considers the objectivity and subjectivity of the process of teaching and learning. From our reflection, we highlight some possible interpretation of what will be competence in the educational process and the characterization of a process of teaching and learning that is meaningful allowing action and reaction in real situations.
\end{abstract}

Keywords: Professional Education. Competence. Meaningful learning.

\section{REFERÊNCIAS}

AUSUBEL, D.P. ; NOVAK, J.D. e HANESIAN, H. (1980). Psicologia educacional. Rio de Janeiro, Interamericana. Tradução ao português, de Eva Nick et al., da segunda edição de Educational psychology: a cognitive view. 623p.

BITENCOURT, C. C. A gestão de competências gerenciais: a contribuição da aprendizagem organizacional. 2001. 320 f. Tese (Doutorado em Administração)- Pós-Graduação em Administração da Universidade Federal do Rio Grande do Sul, Porto Alegre, 2001.

CÊA, G. S. S.; SANDRI, S. Formação geral e mundo do trabalho: horizontes em disputa. Currículo sem Fronteiras, v.8, n.1, p.76-93, jan./jun. 2008.

DINATO, M. R. S. A construção de competências organizacionais - análise a partir dos processos de aprendizagem - estudo de caso da empresa Angelus Ciência e Tecnologia. 2008. 126 f. Dissertação (Mestrado) - Programa de Pós-Graduação em Administração, Universidade Estadual de Londrina, Universidade Estadual de Maringá, Maringá, 2008.

ESLABÃO, L. C. A construção de um currículo por competências: o caso do Curso Técnico em Sistemas de Telecomunicações do CEFET-RS . 2006. 226 f. Dissertação (Mestrado em Educação)-Universidade Federal de Pelotas, 2006. 
FERREIRA, E. E. B. A Percepcao de competencia, autonomia e pertencimento como Indicadores da Qualidade Motivacional de Alunos. 2010. 176 f. Tese (Doutorado em Educação)-Faculdade de Filosofia e Ciências, UNESP, Marília, 2010.

FREIRE, P. Educação como prática da liberdade. 27 ed. Rio de Janeiro: Paz e Terra, 2003.

McCLELLAND, D. C. Testing for Competence Rather Than for "Intelligence". American Psychologist, jan., 1973.

McKERNAN, J. Curriculo \& imaginação: teoria do processo, pedagogia e pesquisa ação. São Paulo: Artmed, 2009.

NUNES, S. C. A inserção da noção de competências em cursos de graduação em administração. 2007. 438 f. Tese (Doutorado em Administração)-Faculdade de Ciências Econômicas da Universidade Federal de Minas Gerais, Belo Horizonte, 2007.

PAIVA, K. C. M. et al. Competências profissionais e interdisciplinaridade no Direito: percepções de discentes de uma faculdade particular mineira. Educ. Pesqui. [online], v.37, n.2, p. 355-373, 2011. ISSN 1517-9702.

PERRENOUD, P. Ensinar: agir na urgência, decidir na incerteza. 2. ed. Porto Alegre: Artmed, 2001.

RAMOS, M. N. A pedagogia das competências: autonomia ou adaptação? São Paulo: Cortez, 2001.

ROGLIO, K. D. Uma análise das ações gerenciais no aperfeiçoamento de processos sob a ótica da aprendizagem organizacional. 1998. 182 f. . Dissertação (Mestrado do Curso de Pós-Graduação em Engenharia de Produção), Departamento de Engenharia de Produção e Sistemas, Universidade Federal de Santa Catarina, Florianópolis, 1998.

SANTOS, J.C.F. O desafio de promover a aprendizagem significativa. Disponível em: $<w w w . j u l i o f u r t a d o . c o m . b r / t e x t o d e s a f i o . p d f>$. Acesso em: 31 maio 2010.

SAVIANI, Dermeval. O choque teórico da politecnia. Trabalho, Educação e Saúde, 1(1):131-152, 2003.

SENGE, Peter M. A quinta disciplina. São Paulo: Best Seller, 2002.

SENO, W.P. Capacitação docente para a educação a distância sob a óptica de competências: um modelo de referência 2007. 221 f. Tese (Doutorado do Programa de Pós-Graduação em Engenharia de Produção e Área de Concentração em Economia, Organizações e Gestão do Conhecimento) - Escola de Engenharia de São Carlos da Universidade de São Paulo, São Carlos, 2007.

SEVERINO, A. J. Metodologia do trabalho científico. 23. ed. São Paulo: Cortez, 2007.

ZARIFIAN, P. Objetivo competência: por uma nova lógica. São Paulo: Atlas, 2001. 


\section{SOBRE OS AUTORES}

Bacharel em Geografia pela Fundação Universidade Federal do Rio Grande-
RS com Formação Pedagógica equivalente à Licenciatura Plena em Geografia
pelo Centro Universitário Augusto Motta-RJ; Especialista em Sociologia Política
e Cultura pela PUC-RJ; Especialista em Planejamento e Educação Ambiental
pela Universidade Cândido Mendes-RJ; Especialista em História do Brasil
pela Universidade Federal Fluminense-RJ; Mestre em Agroecossistemas pela
Universidade Federal de Santa Catarina; Doutorando em Ciência e Tecnologia
Ambiental pela Universidade do Vale do Itajá- SC. Atualmente é professor do
SENAI- Joinville (SC).

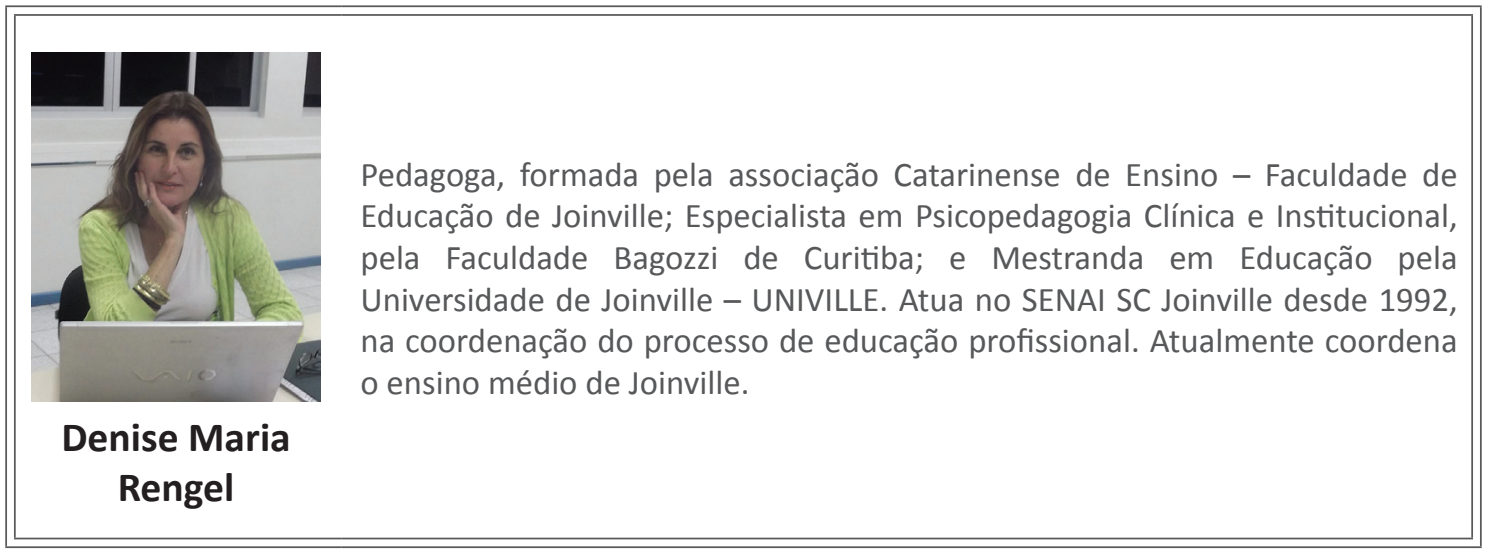

